\title{
Mobile Application with Augmented Reality to Improve Learning in Science and Technology
}

\author{
Miriam Gamboa-Ramos ${ }^{1}$, Ricardo Gómez-Noa ${ }^{2}$, Orlando Iparraguirre-Villanueva ${ }^{3}$ \\ Michael Cabanillas-Carbonell ${ }^{4}$, José Luis Herrera Salazar ${ }^{5}$ \\ Facultad de Ingeniería y Arquitectura, Universidad Autónoma del Perú, Lima, Perú ${ }^{1,2,3}$ \\ Facultad de Ingeniería, Universidad Privada del Norte, Lima, Perú4 \\ Facultad de Ingeniería y Negocios, Universidad Norbert Wiener, Lima, Perú ${ }^{5}$
}

\begin{abstract}
Education has taken a big turn due to the current health situation, and as a result the use of technology has become a great ally of education, achieving important benefits. Augmented reality is being used by teachers and students especially in distance and/or face-to-face learning through didactic learning, self-instruction and the promotion of research. This article shows the development and influence of a mobile application with augmented reality that serves as a reinforcement for the learning of Science and Technology in students of sixth grade of Primary and first year of Secondary School. The Mobile $D$ methodology is used during the development process of the application, the research design is Pre-Experimental since the Pre-Test and Post-Test tests are performed to a single group of students being the total of 30 , obtaining as final result the increase in the level of interest of the students to $100 \%$, in the level of understanding there was an improvement of $50 \%$ and the level of satisfaction is maintained in a range of $40 \%$ satisfaction and very satisfied of $60 \%$, which implies that the application helps them to improve their learning.
\end{abstract}

Keywords-Augmented reality; learning; mobile application; Mobile D methodology

\section{INTRODUCTION}

In this sense, the Program for International Student Assessment (PISA) of the Organización para la Cooperación y el Desarrollo (OCDE), which is carried out every 3 years, evaluates 15-year-old students in the areas of reading, mathematics and science, contributing to systematically assess the knowledge of young people [1].

According to OECD results [2], the 10 countries evaluated in Latin America are below average in Reading and Mathematics, with Peru being one of the countries that is showing small growth. In 2018, Peru participated voluntarily with 342 schools and a total of 8028 students (6086 of whom took the cognitive competency and 1942 took the Financial Education competency) [3], 70\% of which were state schools and $30 \%$ private schools. According to the results obtained by PISA in 2018, the average obtained by Peru were the following: reading comprehension of 401, mathematics of 400 and science of 404 placing it in 64th place out of 77 countries, although in some points a slight improvement has been achieved but it is still worrisome.

In the national evaluations of learning achievements carried out in 2019 [4], [5] where students at 1st secondary school were evaluated, to test if the learning obtained are those expected by the National Curriculum of Basic Education (CNEB), the national results exposed in Table I were obtained, making a comparison of the national results of the year 2018 and 2019. It was identified that we remain in "Level in process", where the student managed to partially learn the expected learning, but still shows difficulties, since the academic performance that students are obtaining is very low compared to other countries.

One of the ways to establish improvements in the educational world is using technological tools [6], [7], these can be used by teachers and students especially in remote and/or face-to-face learning by combining traditional teaching with technology. One of them being Augmented Reality (AR), which consists of the overprinting of one or more virtual elements in real time [8], this is given thanks to the mobile camera being an appropriate means of entertainment for educational purposes.

What we want to achieve in this research is to provide a technological proposal, which will serve to improve the learning of students in the Science and Technology course, thus showing a significant increase in their level of interest in the course, their understanding of the information they are being taught and an increase in their level of satisfaction using the mobile application with reality, thus achieving a dynamic learning.

TABLE I. NATIONAL RESUltS BETWEEN 2018 AND 2019

\begin{tabular}{|l|l|l|}
\hline \multirow{2}{*}{ Areas evaluated } & \multicolumn{2}{|l|}{ Average Mean (MP) } \\
\cline { 2 - 3 } & $\mathbf{2 0 1 8}$ & $\mathbf{2 0 1 9}$ \\
\hline Reading & 571 & 567 \\
\hline Mathematics & 560 & 567 \\
\hline Science and Technology & 500 & 501 \\
\hline
\end{tabular}

II. BIBLIOGRAPHIC STUDY

The accelerated advance of technology together with mobile devices has led us to redefine current teaching and communication methods. A lot of research has conducted studies on the impact of Information and Communication Technologies (ICTs) both in everyday life and in specific areas such as education [9]-[11], aiming to demonstrate the results focused on the skills acquired by students. This technological development can use new technologies as an aid in the teaching and learning process for both teachers and students 
[12]. Adolescents are during these changes and usually make use of the artifacts and technologies that are being incorporated into our daily lives [13], familiarizing themselves with them and allowing them to take advantage of them in a way that contributes to their intellectual development, aiming to achieve an education based on results.

This section presents a review of the latest research conducted regarding the topic in common, to show the benefits and effects achieved from AR implemented in education. Articles from academic journals and academic research databases between the years 2016-2021 were considered, presenting a summarized analysis of studies.

In the research [14], an application was proposed for learning the Quechua language with augmented reality in preschool students, serving as support as teaching material inside and outside the classroom. The activities developed within the application were adapted by means of written and audiovisual comprehension, showing favorable results within the population. A $30 \%$ improvement in the students' performance was evidenced after being used in the classes as a support tool.

In the research work [15] proposes a mobile application called GEO+. The application would be used by elementary school students allowing them to have a better acquisition of knowledge based on the geometry course, making use of augmented reality, and generating a greater interest in the course. The effectiveness of learning was measured through post-test and pre-test evaluations, finally the results obtained were effective regarding the increase of satisfaction and learning before and after the implementation of the application, allowing them the ease of use of technology and achieving autonomous learning.

Finally, the present research [16], shows an application to demonstrate particle physics experiments using AR and the Kinest sensor to create an experience that immerses users in the subject. The results obtained were profitable, according to the qualitative analysis $85 \%$ of the participants were satisfied and recommended the application.

The studies shown allow us to identify how AR has made a great contribution to education.

\section{METHODOLOGY}

The Mobile-D Methodology is used for a collaborative work to deliver a ready product within a maximum of ten weeks by a team of no more than ten developers, including test-driven development, continuous integration, and refactoring, as well as software process improvement tasks [17]. The Mobile-D methodology has 5 phases: Exploration, Initialization, Production, Stabilization and System Testing.

\section{A. Exploration}

At this stage the Stakeholders were established.

- Interest Group: Companies focused on the education sector.

- Application User: (30) Students of 6th Grade of Primary and 1st Grade of Secondary.
- Developers: Researchers/Developers of the present project.

\section{B. Initialization}

In this phase, the technological resources (hardware and software) for the development of the research project are established.

Hardware:

- 2 laptops with 4-core processor or more, 8 GB RAM.

- Samsung A20S mobile device.

Software:

- Unity: This is a video game development tool that also serves to create interactive experiences in Virtual or Augmented Reality [18], being processed, rendered, and displayed in real time.

- Blender: A software capable of creating new 3d visualizations [19] (still images, animations, video editions, etc.), it has a high-quality architecture, allowing an optimal workflow.

- Vuforia: Vuforia is an augmented and mixed reality application development tool, oriented for the Unity engine [20]. Offering text recognition, image recognition, tracking, target detection.

- Visual Studio: is an integrated development environment (IDE) being a program that has several features around software development [21].

\section{Production}

In this phase the ideas are organized, and the functions of the application are prototyped. Fig. 1 shows the general architecture of the application called ARST.

Through the mobile device captures the scene taken through the camera and the Vuforia SDK will create frames of the captured scene converting the image to a different resolution for the proper processing of the tracker. The Vuforia SDK will analyze the images through the tracker looking for similarities in the database that is composed of the targets, and then the application verifies the status of the targets to update the logic programmed in Unity, and finally present the virtual content on the screen of the device to be observed in augmented reality.

\section{Stabilization}

In this stage, the development of the components and the integration between them is carried out.

1) Application prototypes: Fig. 2 (a) shows the design of the main menu of the application, with its respective options where students can interact, then Fig. 2 (b) shows the initial interface of the presentation of the topic to be performed with its respective classification, in Fig. 2 (c), the interface of the ARST Application quiz is shown, finally in Fig. 2 (d), shows the application questionnaire where students interact by asking questions about the topic, giving a score. 


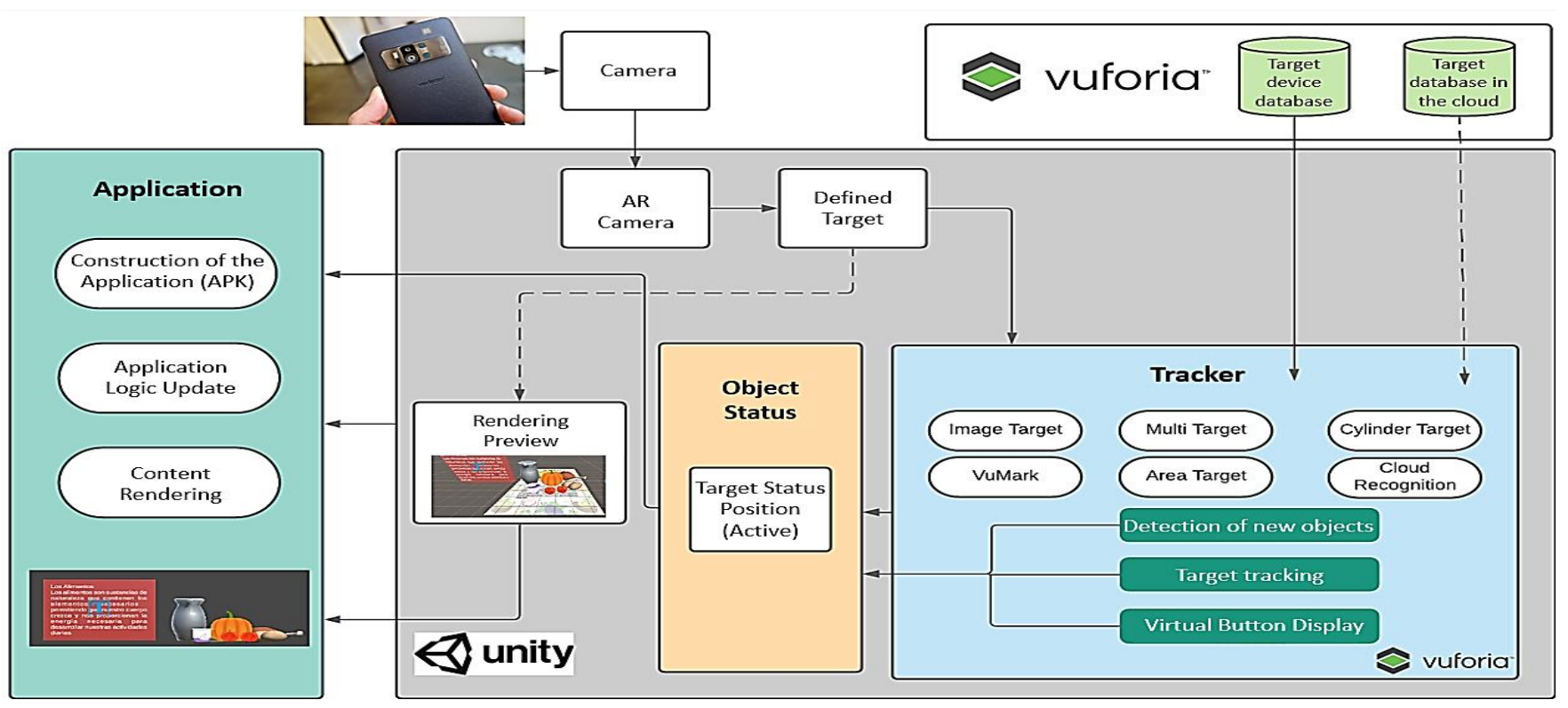

Fig. 1. Project Architecture.

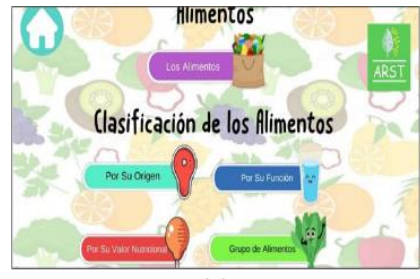

(a)

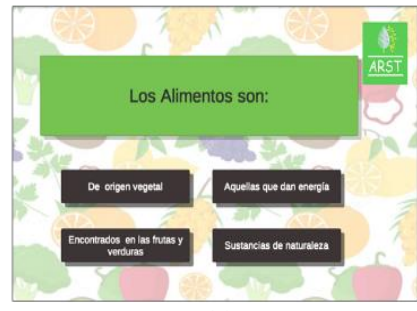

(c)

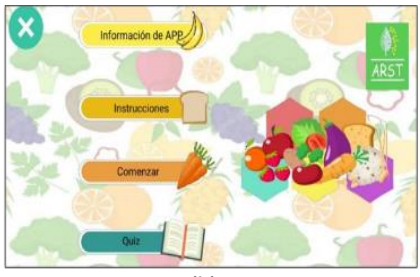

(b)

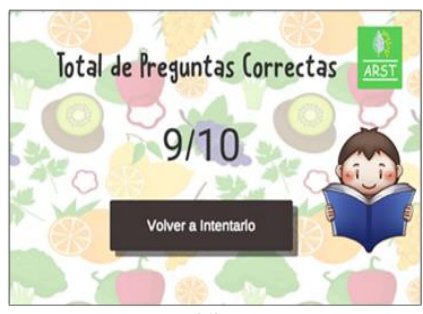

(d)

Fig. 2. Interfaces of the RST Application.

In Fig. 3, when entering the start option, buttons about foods and their classification will be listed, where 3D models of foods and their classification are visualized by means of targets. For example, the food with a brief information, the classification of food (by origin, by nutritional value).

\section{E. Test}

For this research, the population will be made up of 30 students from I.E.P. Magíster in the city of Lima, district of Villa María del Triunfo. It is applied to students in 6th grade of Primary and 1st Grade of Secondary. The design used was preexperimental, with a pre-test and a post-test since the online method was used (1). Table II shows the definition of the items.

Ge $O_{1} \times O_{2}$
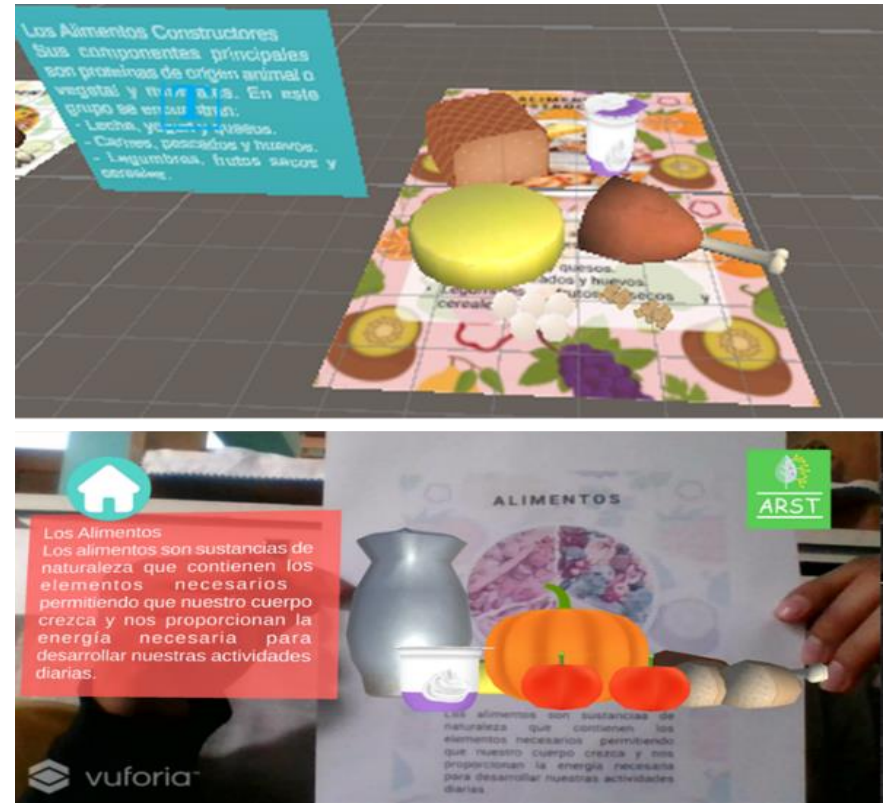

Fig. 3. Visualization of 3D Models of Foodstuffs by means of Targets.

TABLE II. DESCRIPTION OF PRE-EXPERIMENTAL ELEMENTS

\begin{tabular}{|l|l|}
\hline Elements (1) & Description \\
\hline $\mathrm{Ge}$ & Experimental Group \\
\hline $\mathrm{O} 1$ & Level of learning before applying the system. (Pre-test) \\
\hline $\mathrm{X}$ & Mobile application with augmented reality \\
\hline $\mathrm{O} 2$ & Level of learning applied to the system (Post-test) \\
\hline
\end{tabular}




\section{RESULTS}

The objective of this research is to determine to what extent the mobile application with augmented reality will improve learning in the Science and Technology course. For this purpose, the first tests were conducted on one of the most touched topics of the course "Food and its classification", considering the following criteria: The level of interest (KPI1 ), the level of understanding (KPI-2) and the level of satisfaction (KPI-3). The information was collected by means of a survey through the Google Forms platform and the results were analyzed with the SPSS tool. The results are shown in Table III.

The first indicator of level of student interest is measured on a Yes/No scale, the second indicator of level of understanding is evaluated on a scale of Beginning to Outstanding Achievement, and the third indicator of level of satisfaction is evaluated on a scale of Very Dissatisfied to Very Satisfied.

1) KPI-1: Level of student interest: Fig. 4 shows the results obtained from the experimental group with respect to the Pre-Test and Post-Test, it is observed that the level of interest of the students increases by $30 \%$ over the interest they have during the development of the Science and Technology course.

In Fig. 5, the KPI-1 summary report on the level of interest after implementation of the application is shown, which obtained the following results: About $20 \%$ of students do not feel a level of interest and $80 \%$ do with respect to the science and technology course, also through a $95 \%$ confidence interval for the mean, 2 limits 0.61 and 0.99 were obtained.

TABLE III. TEST RESUlts: PRE AND Post

\begin{tabular}{|l|l|l|l|}
\hline Indicators & Group & Pre-Test & Post-Test \\
\hline Level of Interest & Experimental & $78 \%$ & $100 \%$ \\
\hline Level of Understanding & Experimental & $30 \%$ & $50 \%$ \\
\hline Satisfaction Level & Experimental & Very Satisfied & Satisfied \\
\hline
\end{tabular}

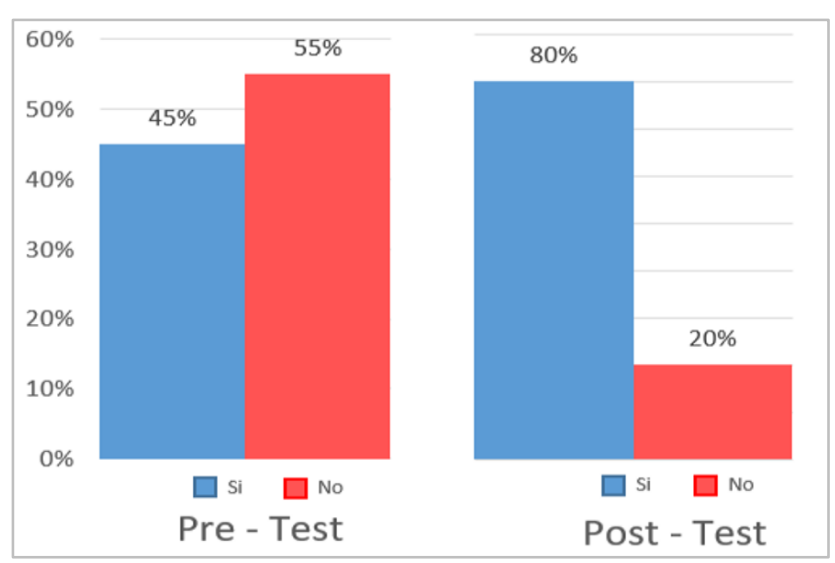

Fig. 4. Pre-Test and Post-Test of Students' Level of Interest.

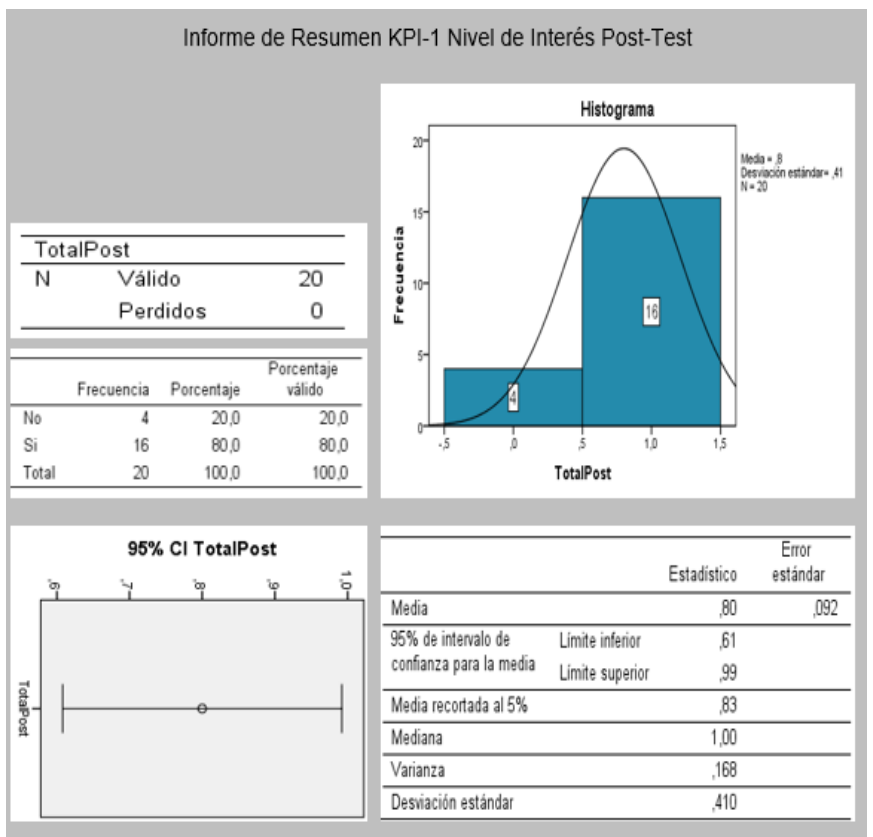

Fig. 5. KPI-1 Summary Report Post-Test Level of Interest.

2) KPI-2: Students' level of understanding: Fig. 6 shows the results obtained by the experimental group with respect to the Pre-Test and Post-Test, showing that the level of understanding of the students has increased by $50 \%$, since half of the students have reached an achievement in their comprehension.

In Fig. 7, the KPI-2 Summary report on the level of understanding after implementation of the application is shown, which obtained the following results: Through the tabulation, $50 \%$ in process, $30 \%$ in Expected Achievement and $20 \%$ in Outstanding Achievement of the students with respect to their level of knowledge and understanding on the topic of Food and its classification of the Science and Technology course, with the use of the mobile application with augmented reality.

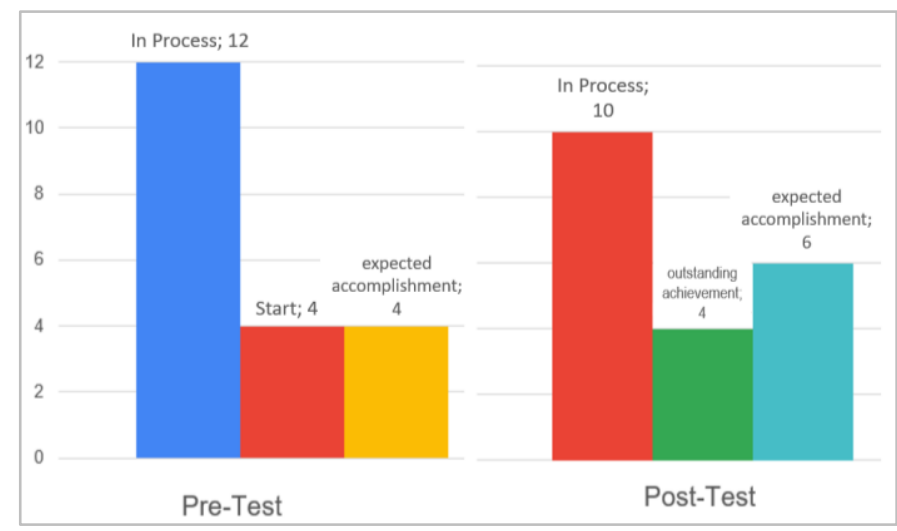

Fig. 6. Pre-test and Post-test of Students' Level of understanding. 


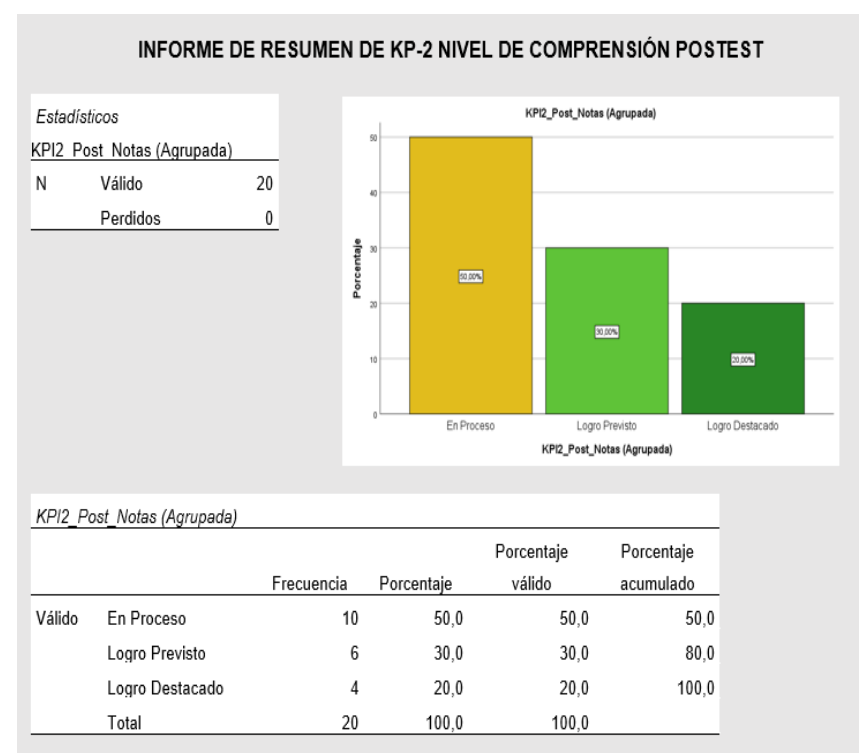

Fig. 7. KPI-2 Post-Test Comprehension Level Summary Report.

3) KPI-3: Student Satisfaction Level: Fig. 8 shows the results obtained by the experimental group with respect to the Pre-Test and Post-Test, showing that the level of satisfaction has decreased, but is still maintained in a degree of satisfaction (Very Satisfied and Satisfied) by the students.

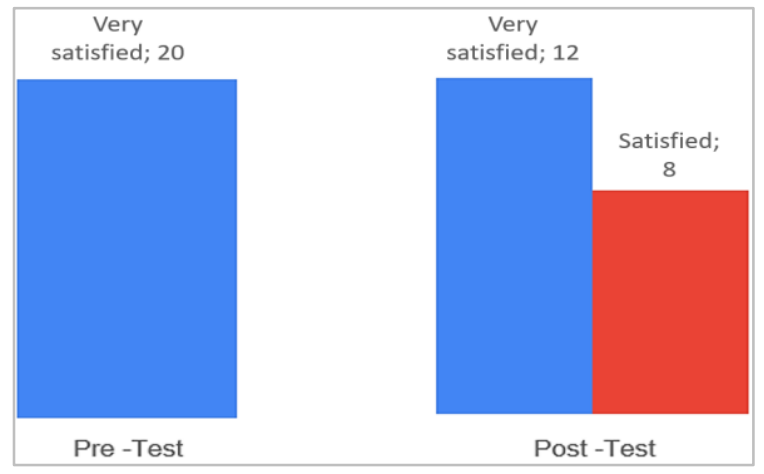

Fig. 8. Pre-test and Post-test of Student Satisfaction Levels.

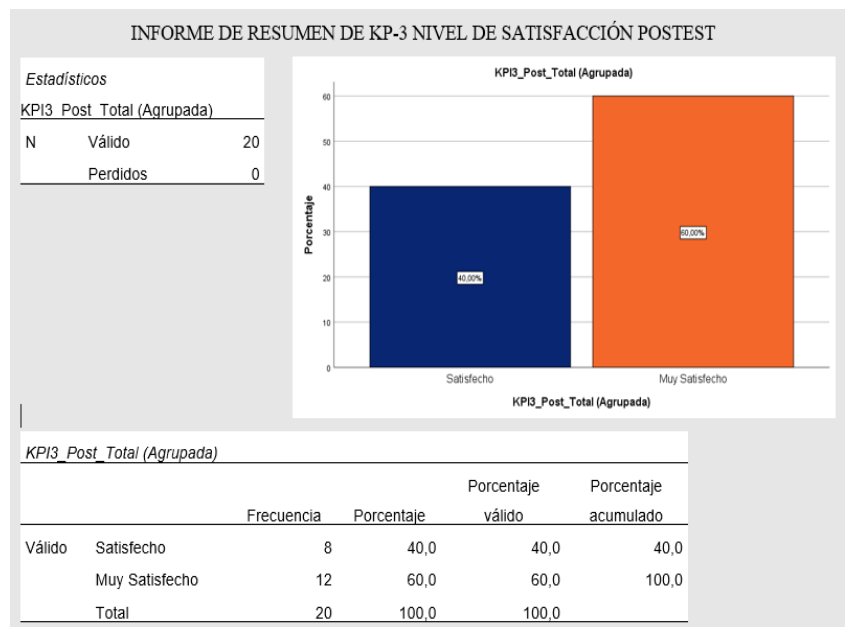

Fig. 9. KPI-3 Post-Test Satisfaction Level Summary Report.
Fig. 9 shows the KPI-3 summary report on the level of satisfaction after implementation of the application, which obtained the following results: Through the tabulation, $40 \%$ of the students feel satisfied and $60 \%$ of the students feel very satisfied with respect to the application with augmented reality applied during the class with the topic of Food and its Classification in the Science and Technology course.

\section{CONCLUSION}

This research article has presented a review of research in recent years regarding the benefits of $\mathrm{AR}$ in education, concluding that it contributes greatly to their academic performance, self-learning, and creativity, in addition to increasing their enthusiasm in courses by encouraging research.

An AR application was developed as a tool to improve learning in the science and technology course for regular elementary school students, providing additional didactic information together with questionnaires to measure learning.

It has been observed that the use of a mobile application with augmented reality significantly improves learning in the Science and Technology Course due to the 50\% increase in the Comprehension Level (Fig. 4 and Fig. 5), applied in the questionnaire of students in 6th grade of primary education and 1 st grade of secondary education (experimental group). There were not many changes in the students' satisfaction (Fig. 6 and Fig. 7), but it remains between the intervals of $40 \%$ of Satisfied Students and $60 \%$ of Very Satisfied Students. There was an increase of $30 \%$ of students who showed interest in the Science and Technology course (Fig. 8 and Fig. 9).

The results showed that the proposed ARST application has succeeded in promoting self-learning, didactic learning, and research. It is recommended for future research to develop more topics applying augmented reality focused on education.

\section{REFERENCES}

[1] Ministerio de Educación y Formación Profesional and Instituto Nacional de Evaluación Educativa, "PISA", España, 2021.

[2] Ministerio de Educación (MINEDU), "PISA: Perú sigue siendo el país de América Latina que muestra mayor crecimiento histórico en matemáticas, ciencia y lectura", 2019. http://umc.minedu.gob.pe/pisaperu-sigue-siendo-el-pais-de-america-latina-que-muestra-crecimientohistorico-en-matematicas-ciencia-y-lenguaje.

[3] Oficina de Medición de la Calidad de los Aprendizajes (UMC) and Ministerio de Educación (MINEDU), “Evaluación PISA 2018," 2018. http://umc.minedu.gob.pe/wp-content/uploads/2020/10/PPT-PISA2018_Web_vf-15-10-20.pdf.

[4] Ministerio de Educación (MINEDU), "Evaluaciones nacionales de logros de aprendizaje. ¿Qué aprendizajes logran nuestros estudiantes?," Perú, 2019. http://umc.minedu.gob.pe/wp-content/uploads/2020/06/ Reporte-Nacional-2019.pdf.

[5] Oficina de Medición de la Calidad de los Aprendizajes (UMC) and Ministerio de Educación (MINEDU), "Evaluaciones de logros de aprendizaje. Resultados 2019,” 2019. http://umc.minedu.gob.pe/wpcontent/uploads/2020/06/PPT-web-ECE-2019-28.05a.pdf.

[6] Saéz Daniela, "La Tecnología e Innovación educativa en el Marco de la pandemia: Lecciones aprendidas," El Diálogo Lidedazco para las Américas, vol. 1, 2020.

[7] C. Marín, R. Vallejo, G. Castro, Q. Mendoza, M. G. Castro, and C. Q. Mendoza, "Innovación y tecnología educativa en el contexto actual latinoamericano / Innovation and Educational Technology in the current 
Latin American context," Rev. Ciencias Soc., vol. 26, 2020, doi: 10.31876/rcs.v26i0.34139.

[8] A. Blázquez Sevilla, "Realidad Aumentada en Educación," 2017. http://oa.upm.es/45985/1/Realidad_Aumentada_Educacion.pdf.

[9] S. V. Raju, M. S. V. S. B. Raju, G. Abbaiah, and M. Gudavalli, "Role of ICT in Outcome Based Education," 2016 IEEE 6th Int. Conf. Adv. Comput., pp. 815-819, Feb. 2016, doi: 10.1109 / IACC.2016.155.

[10] P. R. Rajarapollu and S. A. Bhagwatkar, "ICT - An Effective Way for Active and Collaborative Learning Teaching Process in Engineering Education - A Review," Int. Conf. Transform. Eng. Educ. ICTEE 2017, Dec. 2018, doi: 10.1109/ICTEED.2017.8585697.

[11] J. Gómez Galán, "Innovation and ICT in Education: The Diversity of the 21st Century Classroom," River Publ., 2021. https://ieeexplore.ieee. org/document/9494314.

[12] G. Á. Calero, J. A. Díaz Quiñones, and P. M. Díaz Martínez, "Adolescencia y tecnologías de la información y comunicaciones. Un reto para la sociedad cubana actual Adolescence and information and communication technologies. A challenge for the current Cuban society," Scielo, pp. 30-40, 2018.

[13] A. Barquero and F. Calderón, "Influencia de las nuevas tecnologías en el desarrollo adolescente y posibles desajustes," Cúpula, pp. 11-25, 2016. https://www.binasss.sa.cr/bibliotecas/bhp/cupula/v30n2/art02.pdf.

[14] J. Zapata-Paulini, M. Soto-Cordova, and U. Lapa-Asto, "A Mobile Application with Augmented Reality for the Learning of the Quechua
Language in Pre-School Children," in 2019 IEEE 39th Central America and Panama Convention (CONCAPAN XXXIX), Nov. 2020, pp. 1-5, doi: 10.1109/concapanxxxix47272.2019.8976924.

[15] V. Rossano, R. Lanzilotti, A. Cazzolla, and T. Roselli, "Augmented Reality to Support Geometry Learning," IEEE Access, vol. 8, no. June, pp. 107772-107780, 2020, doi: 10.1109/ACCESS.2020.3000990.

[16] H. Hyder, G. Baloch, K. Saad, N. Shaikh, A. B. Buriro, and J. Bhatti, "Particle Physics Simulator for Scientific Education using Augmented Reality," Int. J. Adv. Comput. Sci. Appl., vol. 12, no. 2, pp. 671-681, 2021, doi: 10.14569/IJACSA.2021.0120284.

[17] J. Gomez and D. Hernandez, "Mobile D (programación dispositivos móviles)," Universidad del Quindío, 2016. https://es.slideshare.net/ pipehernandez1020/mobile-d-programacion-dispositivos-moviles.

[18] Unity, "Unity - Manual: Manual de Unity," 2016. https://docs.unity3d.com/es/530/Manual/UnityManual.html.

[19] Blender, "Introducción — Blender Manual." https://docs.blender.org/ manual/es/2.82/getting_started/about/introduction.html.

[20] Unity, "Vuforia - Unity Manual," 2018. https://docs.unity3d.com/es/ 2018.4/Manual/vuforia-sdk-overview.html.

[21] Microsoft, "IDE de Visual Studio | Visual Basic," 2021. https://docs.microsoft.com/es-es/visualstudio/get-started/visualbasic/visual-studio-ide?view=vs-2019. 